\section{Mental health care failure in England}

\author{
Myth and reality
}

TOM BURNS and STEFAN PRIEBE

The past few years have seen mental health services in England (more so than in the UK generally) subjected to an unprecedented barrage of criticism. The tone has been set by tabloid newspapers ("London's mental health services a shambles" - Evening Standard, 16 January 1996; "We're mad to trust shrinks" - Daily Mirror, 9 February 1996). Fuelled by enquiries into high-profile homicides by the mentally ill, and by concerns over the numbers of disturbed individuals living rough on the capital's streets, these reports have had a profound effect on public confidence in mental health services. It has little impact to point out that the homicide rate by people with mental illness has been stubbomly unaffected by community care policies (Bennett, 1996) and that violence observed in a society is more correlated with unresolved social problems than with the practice of psychiatry, and in particular the proportion of patients treated in community-based services. It appears similarly futile to demonstrate that closures of mental hospitals are not linked to homelessness (Leff, 1993; Craig, 1998). The current, pervasive opinion is that English mental health services (especially in cities) are unacceptably poor (Deahl \& Turner, 1997). The Secretary of State for Health, Frank Dobson, has recently pronounced that "community care has failed", and his predecessors expressed their lack of confidence by imposing a succession of increasingly restrictive legislative requirements - the Care Programme Approach (Department of Health, 1990), the supervision register (Department of Health, 1994) and supervised discharge (Department of Health, 1996).

To make a meaningful overall assessment of performance, a comparitor is necessary. Such a comparison could be either with English services in the past or with services in other equivalent countries. Another possibility is to compare wellfunded with poorly-funded English services in terms of comprehensiveness of provision. Interpreting such internal comparisons is, however, fraught with difficulties, as the differences in funding are unlikely to have arisen arbitrarily. Comparisons with other countries are very complicated, because cultures, political and social traditions and health care systems are so different. Simple like-with-like measures are hard to obtain. Context must be acknowledged (in particular the low UK spend), and complex judgements made (Burns \& Priebe, 1996). Both of us have worked in countries that spend considerably more on mental health care than the UK. S.P. recently moved to east London after practising in Berlin, and T.B. worked for three years in Sweden. Through our academic and research interests we both regularly visit and work with colleagues in these and other European countries. Our personal experience of everyday practice in other countries has made us sceptical of the sweeping criticisms of English mental health care. Our experiences are, however, subjective, and not based on empirical research. Data that link features of mental health care systerns to outcome are hardly available, and further intensive research will be needed to overcome the conceptual and methodological problems associated with such studies when they are conducted.

There are undoubtedly serious shortcomings in the English services. These include the excessive preoccupation with risk, the limited therapeutic involvement of consultants and the shortage of services for patients with less severe mental illnesses, to name just a few. On the other hand, there are aspects of our care which, despite our low health spend, we would suggest compare favourably with much in Europe and North America. Coordination and continuity of care, particularly for those with severe mental illness, are certainly better. The comprehensive approach of sectorised care in the UK (having the same team responsible for in-patient and out-patient care) provides a remarkably flexible response to the needs of this group. Because it is so widespread and so long-established (Johnson \& Thorni- croft, 1993), we take it for granted and seem unaware of what an asset it is. Mental health care is, with few exceptions, within the public domain, and service planning is not solely driven by the economic interests of service providers and insurance companies. Although the past decade has experienced too many service changes, these changes at least demonstrate the flexibility of the system. Service delivery is generally transparent and subject to clinical audit and a widespread consideration of clinical effectiveness. English psychiatrists, correctly preoccupied with the problems generated by the split between health and social care, seem rarely to reflect on the degree to which services are fragmented elsewhere. By international standards our services are extraordinarily straightforward and well coordinated.

In the absence of clear objective criteria for success or failure of community mental health care, and given the (at least partly) favourable comparison with other countries, we can find no justification for the sweeping statement that it has failed.

\section{ORIGINS OF CRITICISM}

The reasons for such a heavily critical stance are probably several. The current reappraisal of all professionals means that psychiatrists, just like other doctors, are subject to increasing questioning. It has probably been marginally more pronounced for us, as our practice has moved from the obscurity of isolated mental hospitals to greater openness and accountability in the communities we serve. These external pressures are important, but much of the criticism arises from within.

In the UK, where the National Health Service (NHS) is a single funding source and has a long history of under-resourcing, 'shroud-waving' has become accepted behaviour for doctors. Insisting on how dire things are is the recognised negotiating position - one that would have disastrous consequences in a market economy, or even in a mixed economy with adequate provision. For example, the impression left by several recent publications (e.g. MILMIS Project Group, 1995; Deahl \& Turner, 1997; King's Fund, 1997) is that services are uniformly poor across London with no available beds and an absence of effective inter-agency working. Yet both of us work in services that always have empty beds to admit acute patients, and both enjoy effective collaboration with local social services. We assume we are not alone in this, and it may be more fruitful 
to investigate and understand these variations than to continue to restate the generality. Making these points is almost embarrassing for us. It seems like letting the side down, blunting the force of the profession's case, rather than (as it really is) ensuring that the picture presented accurately reflects service variations in the capital.

Another important difference between the UK and most of Europe is the relative shortage of doctors. Not only does this make the job difficult, but the security it affords may lead us to highlight service inadequacies rather than resolve them. While the UK may have few doctors compared with other European countries, it is certainly not short of academics or research into community mental health. We have six active research professors of community psychiatry in London alone, and a strong tradition of highly regarded, pragmatic mental health services research. Such research is bound to identify gaps in provision and make recommendations for change. This can give the impression that our services are inferior to those in countries that do not collect such detailed statistics or conduct rigorous studies.

The strongest voices in the debate are often from the teaching hospitals, who may be less qualified to speak for the profession on this matter than on others. Driven by the legitimate demands of teaching and research, they have generally been slower to invest in local service development despite confronting greater than average challenges in inner-city areas. Their experiences have probably been generalised excessively.

\section{IMPACT OF CRITICISMS}

We are concerned that exaggerated and undifferentiated criticism is seriously damaging our services and the morale of our staff. Continuously emphasising how awful things are will deter bright graduates from choosing psychiatry as a profession just as happened in general practice when those practitioners were so vociferously critical of their lot (Jenkins \& Scott, 1998).

Blanket criticism will obscure real and important differences within service provision and thereby prevent important lessons being learnt from what the best services have to teach. These lessons are important both at home and abroad. If the strengths of good services go unrecognised, national policy-makers are denied the opportunity of building upon them and fostering evolutionary improve-

TOMBURNS. FRCPsych, Department of Psychiatry, St George's Hospital Medical School, London; STEFAN PRIEBE, MD. St Barthotomew's and Royal London School of Medicine. Academic Unit. East Ham Memorial Hospital, London

Correspondence: Professor Tom Burns, Department of Psychiatry, Jenner Wing, St George's Hospital Medical School, Cranmer Terrace, London SWI7 ORE, and Pathfinder NHS Trust. Tel: 01817255542 ; Fax: 01817253538

(First received 17 August 1998, final revision 17 November, accepted 17 November 1998)

ments in care. The result is that they will import service models from abroad which either may be inappropriate to the English context (e.g. by neglecting the role of well-developed primary care) or whose clinical advantages have been demonstrated against uncertain control situations (e.g. Solomon, 1992).

Shroud-waving is unlikely to achieve its purpose of generating increased investment in mental health services unless a clear, articulated model in which to invest accompanies it. We have to convince the Government that we know how to lead our services and invest their money wisely. Without a strong clinical lead, their response to the highlighted risk is likely either to be bureaucratic (e.g. the Care Programme Approach, supervision registers) or to turn to alternative sources of advice. The gap left by the profession in planning the shape of services will be filled by others, often much less experienced. There is no shortage of advice about how to reform the mental health services being proffered by pressure groups and voluntary bodies. In many cases their conviction may far exceed evidence for the feasibility or value of their proposals. But if theirs is the only positive advice the Government is getting, we should not be too surprised if it takes it.

Neither one of us doubts the real problems that face modern mental health services. The rules of the game are changing. Family and social changes make coping with severe mental illness increasingly problematic. Public expectations are rising, and in our current, very visible position, balancing therapy with social control is highly delicate. England has always underspent on health services, and we do need to keep pressing for more investment. We should, however, take a much more serious approach to winning public confidence in our work.

If the public (and therefore the Government) is to make informed judgements about the quality of current mental health services, there are at least two prerequisites. The first is to help establish sensible reference points around which evaluations can be made. Comparing one country's service with another is not easy (Burns \& Priebe, 1996), but establishing some anchor points is an essential first step to making sensible judgements about change. The same is true for variations within the NHS services, which have to be described and analysed accurately. The second prerequisite is to take responsibility for what is good in what we do (there is a lot) but also for what we should do differently. This might involve a more prescriptive and consistent approach within the profession than we are currently used to. If we do not do something about it, the enemy within may prove as deadly as the enemies without.

\section{REFERENCES}

Bennect, D. (I99) Homicide, inquiries and scapegoating. Pychiotric Bulketin, 20, 298-300.

Burns, T. A Priobe, S. (I996) Mental health systems and their characteristics: a proposal. Acto Pyychiotrico Scandinovica, 94, 381-386.

Crain, T. (1998) Homelessness and mental health Psychiotric Bulletin, 22, 195-197.

Deaw, M. \& Twrer, T. (ISe7) General psychiatry in no-man's land. British fournal of Psychiatry, 171, 6-8.

Department of Health (19s0) The Core Progromme Approach for People with a Mentol liness Referred to the Speciolist Psychiotric Services. Jint Heath/Social Services Circular HC (90) 23/LASS (90) 11. London:

Department of Health.

- (1994) Introduction of Supervision Registers for Mentally II People from I April 1994. HSG (94) 5 . London: Department of Health.

- (199) Guidance on Supervised Discharge (After Cone (nder Supervision and Related Provisions). Supplement to the Code of Proctice Published August 1993 Pursuont to Section 118 of the Mentol Health Act 1983. London: Department of Health.

Jenkdns, R. \& Soott, J. (1999) Medical staffing crisis in psychiatry. Psychiatric Bulletin, 22, 241.

Johmson, S. \& Thornicroft, G. (1993) The sectorisation of psychiatric services in England and Wales. Social Psychiotry and Psychiatric Epidemiology, 24, 45-47.

Lof, J. (IM) All the homeless people - where do they all come from? British Medical joumal, 306, 669-670.

King's Fund (I997) London Mentol Heatth, The report to the King's Fund London Commission. London: King's Fund.

Mums Project Group (ISys) Monitoring inner London mental illness services. Psychiatric Bulletin, 19, 276-280.

Solomon, P. (1992) The efficacy of case management services for severely mentally disabled clients.

Community Mentol Health fournal, 22. 163-180. 